\title{
Optimization of recycled concrete aggregate geopolymer bricks by Taguchi Method
}

Mariam Farouk Ghazy (Main and Corresponding Author)

Department of Structural Engineering, Faculty of Engineering, Tanta University

Seperbay Campus - Tanta - PC 31733- The Arab Republic of Egypt, Tanta (Egypt)

mariam.ghazy@f-eng.tanta.edu.eg; dr.mariamghazi@yahoo.com

Manuscript Code: 13958

Date of Acceptance/Reception: 08.07.2020/28.09.2019

DOI: 10.7764/RDLC.19.2.244

\begin{abstract}
The experimental program was undertaken to investigate the performance of different geopolymer bricks (GB) made with different amounts of industrial waste materials by Taguchi method. Taguchi approach (with $\mathrm{L}_{16}$ orthogonal array) was used to design the experimental plan to reduce the number of experiments as well as to analysis the results. Recycled concrete aggregates (RCA), marble powder (MP) and limestone powder (LP) were considered as the main variables (control factors) to develop the sustainable geopolymeric concrete designated for building bricks. Four responses where density, mechanical properties (compressive and flexural strengths) at 28 days age and the percentage of water absorption were conducted. The test results revealed that combining an eminently RAC, MP and LP can produce GB with 28 days compressive strength of about $36-58 \mathrm{MPa}$ with ambient temperature. The RCA was the most influential factors on the performance of GB due to its performance contribution. Furthermore, the GB containing RCA is suitable for environment friendly construction and is comparable to a normal GB made with natural aggregate.
\end{abstract}

Keywords: Recycled concrete aggregates, marble powder, limestone powder, geopolymer brick, mechanical properties, Taguchi method.

\section{Introduction}

Large amounts of wastes like fly ash (FA), limestone powder (LP), marble powder (MP), etc. are accumulating in countries all over the world. Most of these wastes are abandoned and cause certain serious environmental problems and health hazards. Geopolymer binder and recycled aggregates (RA) are environment friendly products and is thus considered as part of sustainable development.

Moreover, the recycled concrete aggregates (RCA) are extracted from old concrete and demolished concrete structures and its uses have gained tremendous momentum in constructional engineering in recent years. The use of RCA and RA to preserve natural resources and decrease the amount of disposals in landfills has been growing in the recent years (Surya et al., 2013; Rao et al., 2007). Given the variable characteristics of recycled concrete aggregates while compared to the virgin aggregate sources, there still exists a conservative approach that limits the use of RCA in field implementations (Surya et al., 2013).

The replacement of coarse and fine natural aggregates by RA from construction and demolition waste at the levels of 25 and $50 \%$ had little effect on the compressive strength of the brick and block specimens, but higher levels of replacement reduced the compressive strength. Using RA up to $100 \%$ concrete paving blocks can be produced with a compressive strength of not less than $49 \mathrm{MPa}$ at 28 days (Poon et al., 2002).

Anuar et al. (2011) presented test results of class- C FA geopolymer concrete, made with crushed limestone and RCA as coarse aggregates, and subjected to curing at ambient temperature. The results revealed that RCA could be used as coarse aggregate in geopolymer concrete.

LP was used as partial replacement (10\% and 15\%) in FA based geopolymer. The test results revealed that high strength geopolymer pastes can be produced using mixture of FA with LP and curing temperature at $65{ }^{\circ} \mathrm{C}$ for 48 hours (Dutta \& Ghosh, 2012).

LP was mixed with the FA at levels of 10,20 and $30 \%$ by volume. LP and FA were mixed, wetted and compressed under high pressure in a steel mold. The test results indicated that masonry composites can be produced using $L P, F A$ and water (Turgut, 2010). Moreover, LP, class C- FA, silica fume and water were used without any other components in masonry brick production. The compressive and flexural strengths, density, water absorption, porosity and thermal conductivity of the bricks were measured. The compressive strengths of masonry blocks at the 28 and 90 days curing time, were 23 and 26.5 MPa, respectively at 20\% silica fume content (Turgut, 2012). 
The experimental results of MP-based geopolymer indicated that the compressive strength can reach $44 \mathrm{MPa}$ within 120 minutes setting time at ambient condition. According to the results, MP-based geopolymer has the potential to be used as a new civil engineering construction material (Cheng et al., 2017). The microstructure of geopolymeric green cement contains $\mathrm{C}-\mathrm{S}-\mathrm{H}$ gel and aluminosilicate in the framework.

MP in different proportions of 0-80 wt\% was mixed with industrial brick mortar. These prepared samples were pressed and sintered at three different temperatures 900,1000 and $1100^{\circ} \mathrm{C}$. It was found that the amount of MP additive had positive effect on the physical, chemical and mechanical strength of the produced industrial brick (Bilgin et al., 2012).

The use of MP in concrete or/and mortar production as cement replacement from 0 to 20\% (Yamanel et al., 2019) or as sand replacement (cement addition) gradually enhances both of the mechanical and physical properties of concrete especially with lower w/c ratio. MP showed a filler effect in concrete and had no noticeable role in the hydration process (Aliabdo et al., 2014).

Zhang (2013) presented a state-of-the-art review on utilization of wide variety waste materials to produce bricks with different methods. The research was divided into three general categories based on the methods for producing bricks from waste materials: firing, cementing and geopolymerization. Moreover, the hazardous impacts of the conventional brick manufacturing was covered as well as the attempts of the previous researches in treating the problem properly (Shakir \& Mohammed, 2013).

On the other hand, the polymerization process of the geopolymer composite materials needs heat, so at the time of curing most of the researchers provide oven heat curing but on site it is not possible to cure concrete by oven, so there is need to work o+++n methods of curing for geopolymer concrete (Muduli, 2014; Shinde \& Kadam, 2016).

In the field of design of experiments and optimizing the manufacturing processes, published research studies related to the optimization of a single performance characteristic by Taguchi approach (Ross, 1996; Lin, 2004; Ghazy, 2012; Ramezanianpour et al., 2014; Rivera et al., 2014; Ghazy et al., 2015; Kaushik, 2017; Abd Elaty et al., 2017; Uysal et al., 2018).

This study was carried out on the feasibility of producing a modern structural-strength geopolymer bricks from some industrial wastes in Egypt country, mainly in Tanta city. RCA, MP and LP are the main industrial wastes that were considered. In this research work, the most important factor was to manufacture FA geopolymer building brick by using geopolymerization process under atmospheric curing. The author believes that this study dealing with the Taguchi method is carried out for the first time and it is the most ideal and suitable one for the parametric optimization of the GB technology.

\section{Materials}

Methodology

Low calcium fly ash (FA), classified as class F by ASTM C618 was used as the source of cementitious materials to prepare the geopolymer bricks (GB). It had a specific gravity as well as a Blaine specific surface area of 2.3 and $0.46 \mathrm{~m}^{2} / \mathrm{g}$, respectively. Table 1 shows the chemical and physical properties of used FA. The alkaline solutions (AS) used as an activator were a combination of sodium hydroxide (NH) and sodium silicate solution (NS). NH in flake form with a $98 \%$ purity with a $10 \mathrm{M}$ concentration (1.4 specific gravity) and NS solution $\left(\mathrm{Na}_{2} \mathrm{O}=14.7 \%, \mathrm{SiO}_{2}=29.4 \%\right.$ and water $=55.9 \%$ by mass) were used as alkaline liquid. The NH solution was prepared by dissolving the flakes in tap water. The AS was prepared 30 min prior to its use at ratio 1:2 of NH:NS and constant AS/FA ratio of 0.45 .

Medium well-graded sand with a $100 \%$ passing through sieve No. $4(4.75 \mathrm{~mm})$ was used. Crushed limestone with $12 \mathrm{~mm}$ maximum nominal size was used as natural coarse aggregate (NCA). Both the fine aggregate and NCA conformed to the requirements of Egyptian standard specifications ESS (1101-2002). Recycled concrete aggregates (RCA) were obtained from quality control lab test samples of ready mixed concrete plant at Tanta country. RCA derived from the crushed waste concrete cube samples with concrete compressive strength about 25-30 MPa at 28 days age. The tested concrete samples were crushed by using hand hammer to obtain RCA, and RCA passing through sieve size $4.75 \mathrm{~mm}$ was excluded. Table 2 lists the properties of used aggregates. 
Table 1. Chemical and physical properties of FA, MP and LP (Source: Self-Elaboration).

\begin{tabular}{|c|c|c|c|}
\hline $\begin{array}{c}\text { Chemical } \\
\text { compositions \% }\end{array}$ & FA & MP & LP \\
\hline $\mathrm{SiO}_{2}$ & 56.1 & 1.1 & 0.25 \\
\hline $\mathrm{AL}_{2} \mathrm{O}_{3}$ & 32.19 & 0.75 & 0.25 \\
\hline $\mathrm{Fe}_{2} \mathrm{O}_{3}$ & 9.27 & 0.1 & 0.35 \\
\hline $\mathrm{CaO}$ & 0.86 & 80.1 & 57.1 \\
\hline $\mathrm{MgO}$ & 0.03 & 0.52 & - \\
\hline $\mathrm{Na}_{2} \mathrm{O}$ & 0.04 & 1.1 & - \\
\hline $\mathrm{K}_{2} \mathrm{O}$ & 0.2 & - & - \\
\hline $\mathrm{SO}_{3}$ & 0.15 & 0.55 & - \\
\hline LOI & 1.16 & 15 & 42.05 \\
\hline \multicolumn{4}{|c|}{ Physical properties } \\
\hline $\begin{array}{l}\text { Specific surface area } \\
\qquad\left(\mathrm{cm}^{2} / \mathrm{g}\right)\end{array}$ & 4500 & 3500 & 3000 \\
\hline Specific gravity & 2.4 & 2.7 & 2.65 \\
\hline
\end{tabular}

Table 2. Properties of used aggregates (Source: Self-Elaboration).

\begin{tabular}{lcccc}
\hline \multirow{2}{*}{ Properties } & \multicolumn{2}{c}{ Coarse aggregates } & & Fine aggregates \\
\cline { 2 - 3 } \cline { 5 - 5 } & NCA & RAC & & Sand \\
\hline Fineness modulus & 6.5 & 6.85 & & 2.6 \\
Specific gravity & 2.4 & 2.45 & & 2.55 \\
Water absorption \% & 2 & 3.5 & & - \\
Crushing value \% & 21 & 26 & \\
Los Angeles abrasion \% & 30 & 38 & - \\
Size, mm & 12 & 12 & \\
\hline
\end{tabular}

Marble waste powder (MP) obtained from marble factories as a by-product resulted from marble cutting and shaping process was used as an additive to brick mixes. MP used was obtained in wet form as slurry; therefore it was dried in sun then manually sieved through sieve $0.3 \mathrm{~mm}$. Limestone powder (LP) (pure calcite) from quarry wastes with particle passing from $0.3 \mathrm{~mm}$ sieve size was used as an addition to FA by weight. The chemical and physical properties of used MP and LP are given in Table 1.

\section{Specimen preparation, curing and test methods}

All test specimens were prepared with a FA: sand: coarse aggregates ratio equal to 1: 1.5: 3 and adequate constant AS/FA ratio at 0.45 was selected, which the concrete workability can be improved by the correct quantity of water and the correct proportioning and grading of the RCA which can provide practical formulations.

The GB mixtures were mixed in a $100 \mathrm{~L}$ drum mixer. Both of the FA and AS were first mixed for 3 min. Then, sand was continuously added and mixed for $3 \mathrm{~min}$. MP was then slowly added to the mix and the mixing continued until the MP was well dispersed (at least for $3 \mathrm{~min}$ ). The NCA in addition to RCA (if applicable) was added and the mixing was continued for $4 \mathrm{~min}$. Finally, LP was added and the mixing was continued until the mixture was glossy and well combined (at least for $3 \mathrm{~min}$ ).

After casting by using steel molds, compaction was carried out by applying a forming pressure at 1 MPa for 1 min, the specimens were covered and kept at laboratory temperature for one day at $25{ }^{\circ} \mathrm{C}$ and $50 \%$ RH prior to stripping. Followed by air curing and bask in the sun curing in outside the laboratory until they were tested at 28 days age. Figure 1 shows the outdoor temperatures along the May-June month (which the specimens cured in this time).

Prismatic GB specimens with dimensions of $100 \times 60 \times 250 \mathrm{~mm}^{3}$ were used for the density, water absorption, compression, and flexure tests. A hydraulic testing machine with a total capacity of $2000 \mathrm{kN}$ was used for testing specimens in compression and a $300 \mathrm{kN}$ capacity Universal Testing Machine with data acquisition system was used to test specimens in flexure. Tests were conducted according to ASTM C67 to evaluate physical and mechanical properties. 


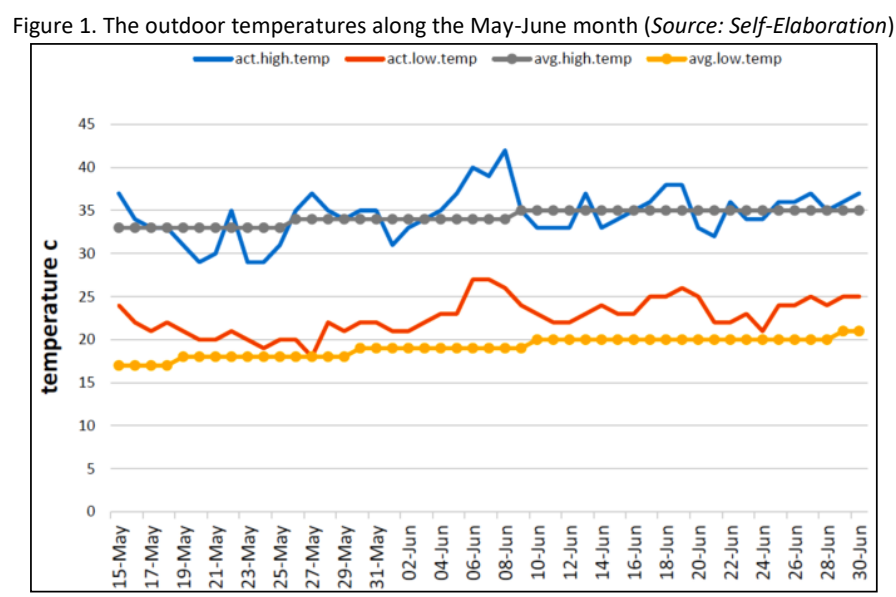

\section{Experimental plan}

In this study, three parameters were used as control factors, namely RCA\%, MP\% and LP\%. The Taguchi method was employed to design the experimental work; however no effort has been made to investigate the effect of using different variables on GB properties. Therefore, an appropriate orthogonal array $(O A) L_{16} O A$ was selected for this investigation. The three independent variables (control factors) and their levels are listed in Table 3 . The details of the mixture proportions are given in Table 4. A statistical Minitab V16 software was used to develop the experimental plan and for to analyze the measured data.

\begin{tabular}{cccc}
\multicolumn{5}{c}{ Table 3. Levels of variables used in experiment (Source: Self-Elaboration). } \\
\cline { 2 - 4 } & \multicolumn{3}{c}{ Variables (control factors) } \\
\cline { 2 - 4 } Level & $\begin{array}{c}\text { A (RCA\%) } \\
\text { (Recycled concrete } \\
\text { aggregates \%) }\end{array}$ & $\begin{array}{c}\text { B (MP\%) } \\
\text { (Marble } \\
\text { powders \%) }\end{array}$ & $\begin{array}{c}\text { C (LP\%) } \\
\text { (Limestone } \\
\text { powders \%) }\end{array}$ \\
\hline 1 & 0 & 0 & 0 \\
2 & 20 & 5 & 5 \\
3 & 40 & 10 & - \\
4 & 60 & 15 & - \\
\hline
\end{tabular}

\begin{tabular}{|c|c|c|c|c|c|c|c|c|c|c|c|c|}
\hline \multirow{2}{*}{$\begin{array}{l}\text { Mix } \\
\text { No. }\end{array}$} & \multirow{2}{*}{$\begin{array}{c}\text { Mix } \\
\text { Code }^{*}\end{array}$} & \multicolumn{3}{|c|}{ Variables (\%) } & \multicolumn{8}{|c|}{ Proportions, $\mathrm{kg} / \mathrm{m}^{3}$} \\
\hline & & RCA & MP & LP & FA & Sand & MP & LP & NCA & RCA & $\mathrm{NH}$ & NS \\
\hline 1 & ROMOLO & 0 & 0 & 0 & 400 & 577 & 0 & 0 & 1156 & 0 & 60 & 120 \\
\hline 2 & ROM5LO & 0 & 5 & 0 & 400 & 577 & 20 & 0 & 1156 & 0 & 60 & 120 \\
\hline 3 & ROM10L5 & 0 & 10 & 5 & 400 & 577 & 40 & 20 & 1156 & 0 & 60 & 120 \\
\hline 4 & R0M15L5 & 0 & 15 & 5 & 400 & 577 & 60 & 20 & 1156 & 0 & 60 & 120 \\
\hline 5 & R2OMOLO & 20 & 0 & 0 & 400 & 577 & 0 & 0 & 924.8 & 231.2 & 60 & 120 \\
\hline 6 & R20M5LO & 20 & 5 & 0 & 400 & 577 & 20 & 0 & 924.8 & 231.2 & 60 & 120 \\
\hline 7 & R20M10L5 & 20 & 10 & 5 & 400 & 577 & 40 & 20 & 924.8 & 231.2 & 60 & 120 \\
\hline 8 & R20M15L5 & 20 & 15 & 5 & 400 & 577 & 60 & 20 & 924.8 & 231.2 & 60 & 120 \\
\hline 9 & R40MOL5 & 40 & 0 & 5 & 400 & 577 & 0 & 20 & 693.6 & 462.5 & 60 & 120 \\
\hline 10 & R40M5L5 & 40 & 5 & 5 & 400 & 577 & 20 & 20 & 693.6 & 462.5 & 60 & 120 \\
\hline 11 & R40M10L0 & 40 & 10 & 0 & 400 & 577 & 40 & 0 & 693.6 & 462.5 & 60 & 120 \\
\hline 12 & R40M15L0 & 40 & 15 & 0 & 400 & 577 & 60 & 0 & 693.6 & 462.5 & 60 & 120 \\
\hline 13 & R60MOL5 & 60 & 0 & 5 & 400 & 577 & 0 & 8 & 462.5 & 693.6 & 60 & 120 \\
\hline 14 & R60M5L5 & 60 & 5 & 5 & 400 & 577 & 20 & 8 & 462.5 & 693.6 & 60 & 120 \\
\hline 15 & R60M10L0 & 60 & 10 & 0 & 400 & 577 & 40 & 0 & 462.5 & 693.6 & 60 & 120 \\
\hline 16 & R60M15L0 & 60 & 15 & 0 & 400 & 577 & 60 & 0 & 462.5 & 693.6 & 60 & 120 \\
\hline
\end{tabular}

*Production method by compacting (1 MPa) and atmospheric curing temperature.

In the Taguchi method, a quality loss function or mean square deviation (MSD) is used to calculate the deviation between the experimental value and the desired value (Ross, 1996). In this investigation, the objective was to maximize 
the strengths; therefore, "larger-is-better" and to minimize the water absorption therefore, "smaller-is-better" quality characteristics were selected.

The MSD of the higher-the-better can be expressed as Eq. (1):

$$
\mathrm{MSD}=\frac{1}{n} \sum_{i=1}^{n} \frac{1}{y_{i}^{2}}
$$

The MSD of the lower is-the-better can be expressed as Eq. (2):

$$
\mathrm{MSD}=\frac{1}{n} \sum_{i=1}^{n} y_{i}^{2}
$$

Where: y: represents the experimental observed value of the experiments, and $\mathrm{n}$ : is the number of times each experiment is repeated.

The value of the loss function is further transformed into a signal-to-noise ratio ( $\mathrm{S} / \mathrm{N})$. Here, the terms signal represents the desirable value (mean) and the noise represents the undesirable value (standard deviation). Thus, the $\mathrm{S} / \mathrm{N}$ ratio represents the amount of deviation present in the performance. The $\mathrm{S} / \mathrm{N}$ ratio can be expressed as Eq. (3):

$$
(S / N)=-10 \log \left(M S D_{i}\right)
$$

\section{Results and discussion}

Table 5 presents the experimental test results of $\mathrm{L}_{16} \mathrm{OA}$ and their corresponding $\mathrm{S} / \mathrm{N}$ using Eqs. (1-3). Figures 2-3 show the test results of the experiment. The density of GB made with RAC is slightly higher ( $6 \%)$ than GB made with NCA up to $60 \%$ replacement.

Generally, the water absorption of RCA was higher than that of NCA. Hence, before the start of the mixing operation,

\begin{tabular}{|c|c|c|c|c|c|c|c|c|}
\hline $\begin{array}{l}\text { Mix } \\
\text { No. }\end{array}$ & $\begin{array}{l}\text { Mix } \\
\text { code }\end{array}$ & $\begin{array}{c}\text { Density, } \\
\mathrm{t} / \mathrm{m}^{3}\end{array}$ & $\begin{array}{c}\text { Comp. } \\
\text { Stre., } \\
\mathrm{MPa}\end{array}$ & $\begin{array}{l}\text { Flex. } \\
\text { Stre., } \\
\mathrm{MPa}\end{array}$ & Abso. \% & $\begin{array}{l}\text { S/N } \\
\text { Com. }\end{array}$ & $\begin{array}{l}S / N \\
\text { flex. }\end{array}$ & $\begin{array}{l}\text { S/N } \\
\text { Abso. }\end{array}$ \\
\hline 1 & ROMOLO & 2.4 & 55 & 4.6 & 1.9 & 34.81 & 13.26 & -5.6 \\
\hline 2 & R0M5L0 & 2.42 & 50 & 4.4 & 1.9 & 33.98 & 12.87 & -5.6 \\
\hline 3 & ROM10L5 & 2.38 & 48 & 4 & 2.3 & 33.62 & 12.04 & -11.4 \\
\hline 4 & R0M15L5 & 2.4 & 50 & 5.2 & 2.0 & 33.98 & 14.32 & -6.0 \\
\hline 5 & R20MOLO & 2.43 & 46 & 6.5 & 1.1 & 33.26 & 16.26 & -0.8 \\
\hline 6 & R20M5L0 & 2.41 & 49 & 6.1 & 1.3 & 33.80 & 15.71 & -2.3 \\
\hline 7 & R20M10L5 & 2.58 & 51 & 5.2 & 2.5 & 34.15 & 14.32 & -8.0 \\
\hline 8 & R20M15L5 & 2.41 & 58 & 5.6 & 1.8 & 35.27 & 14.96 & -5.1 \\
\hline 9 & R40MOL5 & 2.47 & 40 & 4.4 & 3.1 & 32.04 & 12.87 & -9.8 \\
\hline 10 & R40M5L5 & 2.4 & 42 & 5 & 2.4 & 32.46 & 13.98 & -7.6 \\
\hline 11 & R40M10L0 & 2.44 & 58 & 5.9 & 2.0 & 35.27 & 15.42 & -6.0 \\
\hline 12 & R40M15L0 & 2.66 & 47 & 4.9 & 2.4 & 33.44 & 13.80 & -7.6 \\
\hline 13 & R60MOL5 & 2.46 & 40 & 5.4 & 3.3 & 32.04 & 14.65 & -12.7 \\
\hline 14 & R60M5L5 & 2.41 & 37 & 4.3 & 2.6 & 31.36 & 12.67 & -8.3 \\
\hline 15 & R60M10L0 & 2.4 & 43 & 4.8 & 2.6 & 32.67 & 13.62 & -8.3 \\
\hline 16 & R60M15L0 & 2.41 & 53 & 5.2 & 2.9 & 34.49 & 14.32 & -9.2 \\
\hline
\end{tabular}
the saturated surface dry condition of RCA was maintained more than of NCA, which retained low moisture (low water absorption) and easy moisture lost (Cheng et al., 2017).

According to the performed experiment design, it is clearly observed from Table 5 that Experiments No. 8 and No. 11 are the best process parameters setting for maximum compressive strength at $58 \mathrm{MPa}$ for both mixes R20M15L5 and R40M10L0 that manufactured with (20\% RCA, 15\% MP and 5\% LP) and (40\% RCA, 10\% MP and 0\% LP), respectively. These GB mixes produced slightly higher compressive strength with $2.8 \%$ than those of GB containing NCA mix ROMOLO 
which satisfy the ASTM C902. It is possible the high concentration of NH could be leach Si and Al ions from the surface of adhered mortar and leads to higher extent of dissolution (Aliabdo et al., 2014).
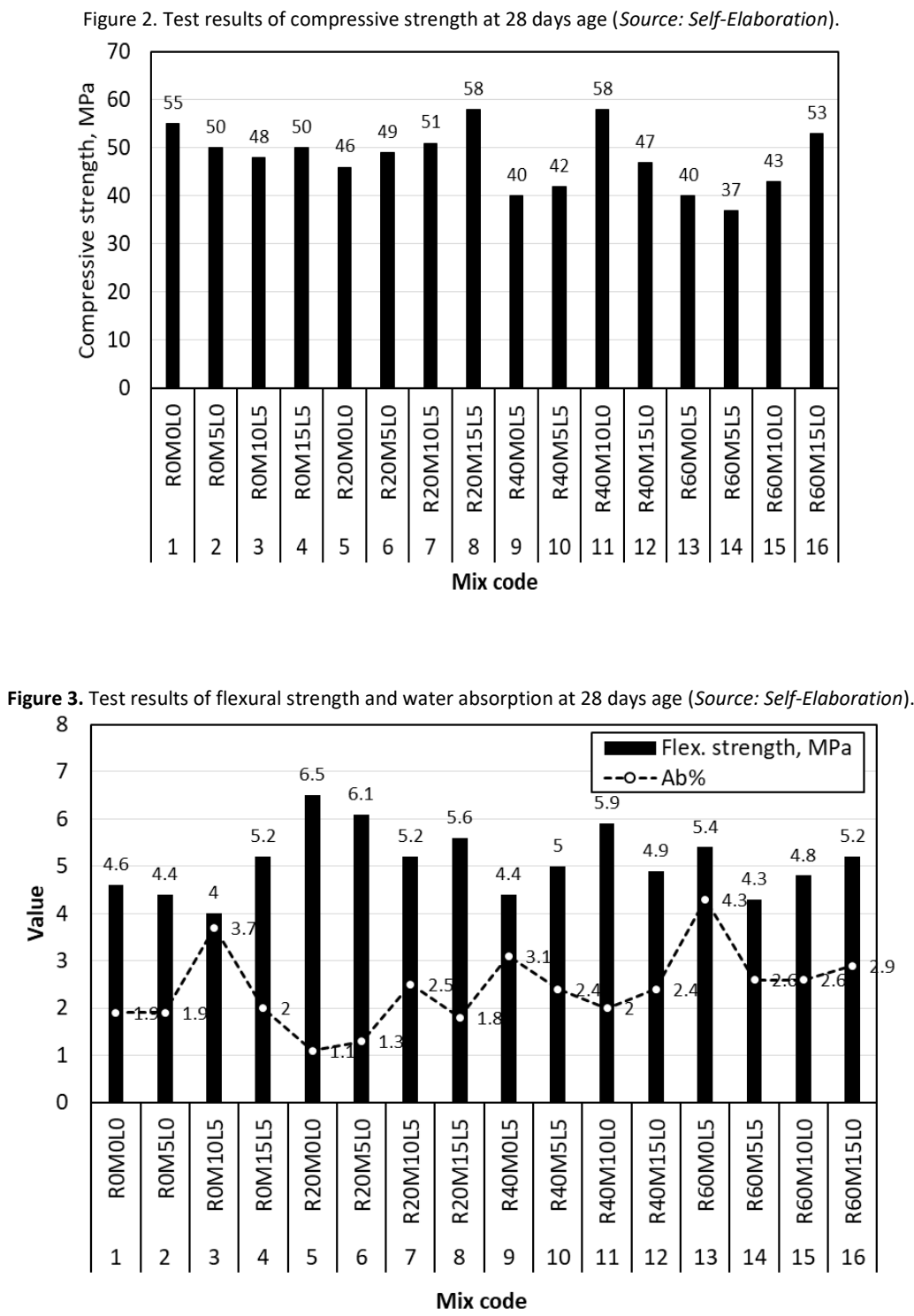

The means of compressive strength of GB for each level are shown in Table 6 and plotted in Fig. 4a. Regardless of the category of the performance characteristics, the largest mean corresponds to better performance. Therefore, the optimal level of the process parameters is the level with the greatest mean. Based on the data presented in Table 6 the optimal combination of compressive strength was obtained at $\left(A_{2} B_{4} C_{1}\right) 20 \% R C A, 15 \% \mathrm{MP}$ and $0 \%$ LP. As a result, the factor/level combination $\mathrm{A}_{2} \mathrm{~B}_{4} \mathrm{C}_{1}$ was recommended. Moreover, factor $\mathrm{A}$ (RCA\%) recorded a maximum value of delta (7.75) and thus had the most significant influence on the compressive strength (Rank 1). It can be seen that the contribution of factor $A$ to the compressive strength was the largest (39.48\%). It can be seen in Table 6 that the strongest influence was exerted by factor A (RCA\%) (Rank 1), factor B (MP\%) (Rank 2), and factor C (LP\%) (Rank 3), respectively.

Therefore, it can be postulated that $\mathrm{C}-\mathrm{S}-\mathrm{H}, \mathrm{C}-\mathrm{A}-\mathrm{H}$ or both are mainly responsible for the strength development that occurs during hydration of class F. The fact that LP does not chemically react was found by Ye et al. (2007). They also reported that cement paste blended with LP shows rapid chemical reaction in the early stages and the interface between the LP and the hydrates is quite porous. Basumajumdar et al. (2008) reported that the compaction pressure of the mixture enhances the intergranular contact, thus facilitating the progress of the reaction by increasing the formation of more interfacial contact areas between the reactants. 
Figure 4. Mean effects plot (Source: Self-Elaboration).
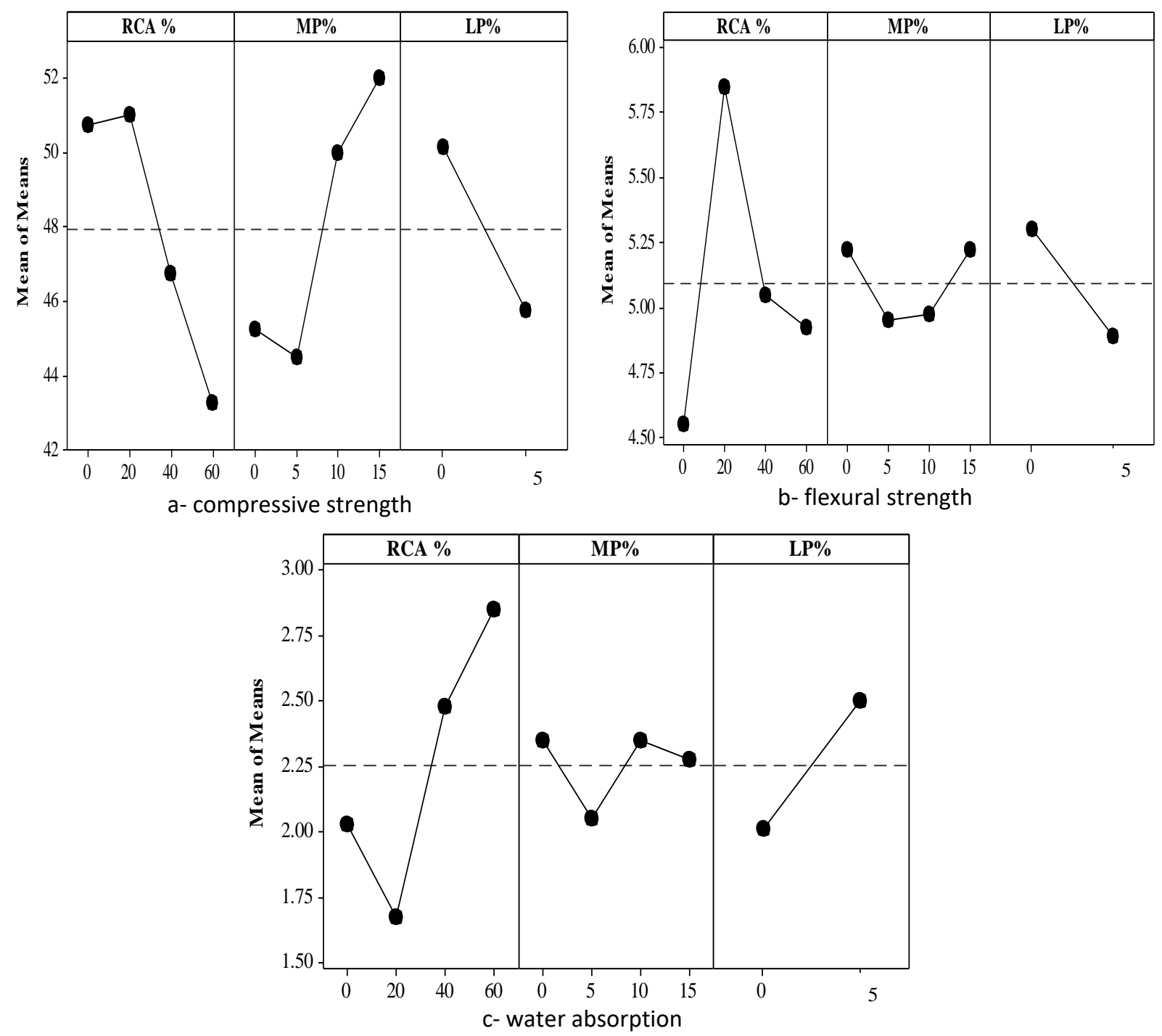

The same analysis procedure can also be applied to optimize the GB properties for the flexural strength and water absorption ratio. Their response tables of means are listed in Table 6 and plotted in Figure 4 ( $4 b$ and $4 c$ ), respectively. The levels that gave the largest average response were selected from the response tables. They were the factor/level combinations of $\mathrm{A}_{2} \mathrm{~B}_{4} \mathrm{C}_{1}$ for the flexural strength and $\mathrm{A}_{2} \mathrm{~B}_{2} \mathrm{C}_{1}$ for the water absorption ratio. The results showed that the RCA\% (factor A) was the most important factor (Rank 1 ) and its contributions were $65.4 \%$ and $59.9 \%$, respectively for the flexural strength and water absorption ratio. It can also be seen that the LP\% (factor C) was quite an important factor (Rank 2) for the flexural strength and water absorption ratio because of its contributions $20.8 \%$ and $24.9 \%$, respectively. The most significant influence was arranged in ascending order by factor A (RCA\%) (Rank 1), factor C (LP\%) (Rank 2) and factor B (MP\%) (Rank 3).

Because the optimal combination of process parameters was selected out of the response tables according to the Taguchi analysis, confirmation tests were processed. It is a good idea to plan on running a few additional samples at the optimum condition. The confirmation tests serve two purposes: first, they establish the new performance at the improvement achieved; and second, they allow the experimenter to determine how close the estimate is to the results observed. The expected result was considered to be confirmed when the mean of a number of samples tested at the optimum condition falls close to it. The results of the confirmation experiment were compared with the worst conditions of the design operating parameters in the experimental plan.

The estimated $\mathrm{S} / \mathrm{N}$, using the optimal parameters for the three responses, can then be obtained and the corresponding actual values can also be calculated by using Eqs. (1-3). It was observed from Table 5, that Experiment No. 14 has the worst value of compressive strength at $37 \mathrm{MPa}$ compared to the other runs. Therefore, it can be concluded that Experiment No. 14 possesses initial setting parameters for this response. Table 6 shows the results of the confirmation 
experiment using the optimal parameters for all responses. A good agreement between the predicted performance and actual performance is shown. The improvement for the individual performance characteristic is shown in Table 6.

\begin{tabular}{|c|c|c|c|c|c|c|c|c|c|}
\hline \multirow[b]{2}{*}{ Level } & \multicolumn{3}{|c|}{$\begin{array}{c}\text { Compressive strength } \\
\text { (larger-is-better) }\end{array}$} & \multicolumn{3}{|c|}{$\begin{array}{l}\text { Flexural strength } \\
\text { (larger-is-better) }\end{array}$} & \multicolumn{3}{|c|}{$\begin{array}{c}\text { Absorption } \\
\text { (smaller-is-better) }\end{array}$} \\
\hline & $\begin{array}{c}\text { RCA\% } \\
(\mathrm{A})\end{array}$ & $\begin{array}{l}\mathrm{MP \%} \\
(\mathrm{B}) \\
\end{array}$ & $\begin{array}{l}\text { LP\% } \\
\text { (C) }\end{array}$ & $\begin{array}{c}\text { RCA\% } \\
(\mathrm{A}) \\
\end{array}$ & $\begin{array}{c}\mathrm{MP} \% \\
(\mathrm{~B}) \\
\end{array}$ & $\begin{array}{l}\text { LP\% } \\
(\mathrm{C}) \\
\end{array}$ & $\begin{array}{l}\text { RCA\% } \\
(\mathrm{A})\end{array}$ & $\begin{array}{c}\mathrm{MP \%} \\
(\mathrm{B}) \\
\end{array}$ & $\begin{array}{c}\mathrm{LP} \% \\
(\mathrm{C}) \\
\end{array}$ \\
\hline 1 & 50.75 & 45.25 & 50.13 & 4.55 & 5.225 & 5.3 & 2.03 & 2.35 & 2.01 \\
\hline 2 & 51 & 44.5 & 45.75 & 5.85 & 4.95 & 4.89 & 1.68 & 2.05 & 2.5 \\
\hline 3 & 46.75 & 50 & - & 5.05 & 4.98 & - & 2.48 & 2.35 & - \\
\hline 4 & 43.25 & 52 & - & 4.93 & 5.23 & - & 2.85 & 2.28 & - \\
\hline Delta & 7.75 & 7.5 & 4.38 & 1.3 & 0.275 & 0.413 & 1.18 & 0.3 & 0.49 \\
\hline Rank & 1 & 2 & 3 & 1 & 3 & 2 & 1 & 3 & 2 \\
\hline $\begin{array}{c}\text { Contribution } \\
\%\end{array}$ & 39.48 & 38.21 & 22.31 & 65.4 & 13.83 & 20.8 & 59.9 & 15.23 & 24.9 \\
\hline $\begin{array}{c}\text { Optimal } \\
\text { combination }\end{array}$ & \multicolumn{3}{|c|}{$\mathrm{A}_{2} \mathrm{~B}_{4} \mathrm{C}_{1}$} & \multicolumn{3}{|c|}{$\mathrm{A}_{2} \mathrm{~B}_{4} \mathrm{C}_{1}$} & \multicolumn{3}{|c|}{$\mathrm{A}_{2} \mathrm{~B}_{2} \mathrm{C}_{1}$} \\
\hline $\begin{array}{l}\text { Predicted } \\
\text { value }\end{array}$ & \multicolumn{3}{|c|}{$57.25 \mathrm{MPa}$} & \multicolumn{3}{|c|}{$6.19 \mathrm{MPa}$} & \multicolumn{3}{|c|}{-} \\
\hline $\begin{array}{l}\text { Experimental } \\
\text { value }\end{array}$ & \multicolumn{3}{|c|}{$56.5 \mathrm{MPa}$} & \multicolumn{3}{|c|}{$6.05 \mathrm{MPa}$} & \multicolumn{3}{|c|}{$1.3 \%$} \\
\hline $\begin{array}{c}\text { Initial setting } \\
\text { parameters } \\
\text { (worst } \\
\text { combination) }\end{array}$ & \multicolumn{3}{|c|}{$\mathrm{A}_{4} \mathrm{~B}_{2} \mathrm{C}_{2}$} & \multicolumn{3}{|c|}{$\mathrm{A}_{1} \mathrm{~B}_{3} \mathrm{C}_{1}$} & \multicolumn{3}{|c|}{$\mathrm{A}_{4} \mathrm{~B}_{1} \mathrm{C}_{1}$} \\
\hline $\begin{array}{l}\text { Measured } \\
\text { value }\end{array}$ & \multicolumn{3}{|c|}{$37 \mathrm{MPa}$} & \multicolumn{3}{|c|}{$4 \mathrm{MPa}$} & \multicolumn{3}{|c|}{ 4.3 MPa } \\
\hline $\begin{array}{l}\text { Improvement } \\
\text { ratio }\end{array}$ & \multicolumn{3}{|c|}{1.33} & \multicolumn{3}{|c|}{2.3} & \multicolumn{3}{|c|}{ - } \\
\hline
\end{tabular}

It was therefore found that the optimal factor/level combination, or the most important factor, for one quality was usually different from that for another quality. In such a case, an engineering judgment that refers to past experience is the only real guarantee for a correct decision-making in the GB process. Based on the experimental result in Table 5, the models for responses, compressive strength, flexural strength and water absorption were formulated as follows (Eqs. (4-6)):

Compressive strength, $\mathrm{MPa}=50.275-0.1338 \mathrm{RCA} \%+0.515 \mathrm{MP} \%-2.188 \mathrm{LP} \%$

Flexural strength, $\mathrm{MPa}=5.248+0.00163 \mathrm{RCA} \%+0.0005 \mathrm{MP} \%-0.2063 \mathrm{LP} \%$

Absorption $\%=1.51+0.0164$ RCA $\%+0.0015 \mathrm{MP} \%+0.2438 \mathrm{LP} \%$

To show the sensitivity of the results, a contour plot for compressive strength was drawn, as shown in Figure 5 . The near-optimal region was located close to the right-hand upper region of the plot, and had a compressive strength value greater than $50 \mathrm{MPa}$, this value gradually reducing as we move left and upwards on the plot. The results show that the optimal value of compressive strength was achieved under lower values of RCA\% and higher values of MP\%. In addition, it can be seen that the shapes of the contour plot give a general idea of the responses at various values of RCA\% and MP\%. 


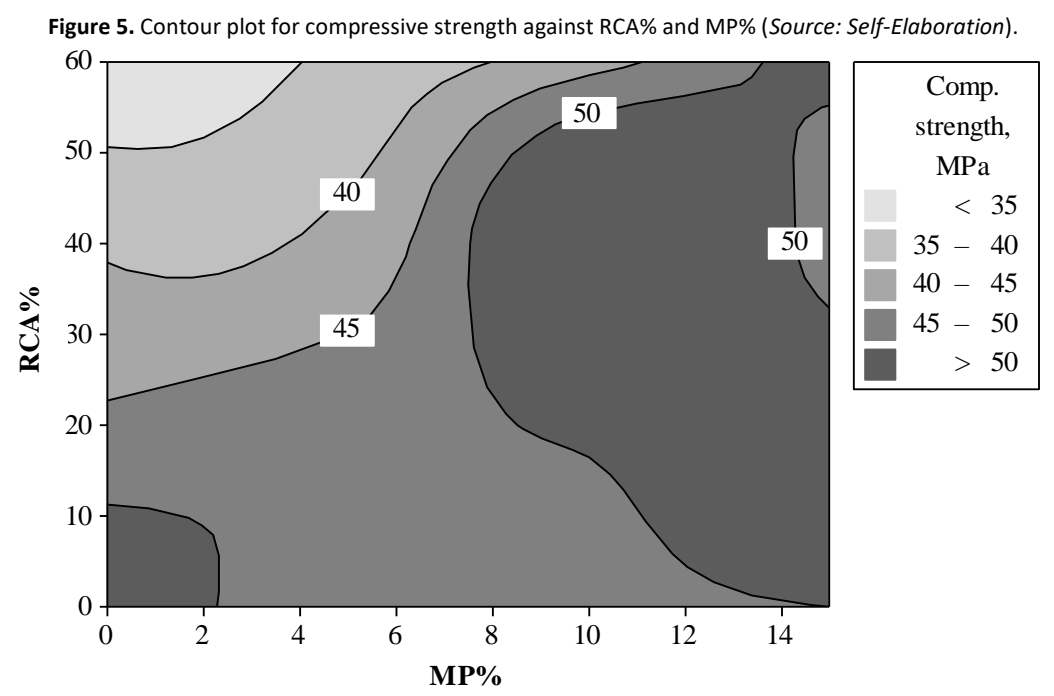

Figure 6 shows the contour plot for the flexural strength. The near-optimal region was located close to the center region of the plot, and had a flexural strength value greater than $6 \mathrm{MPa}$, this value gradually reducing as we move upwards and downwards on the plot. The results show that the optimal value was achieved under higher values of RCA\% and lower values or MP\%.

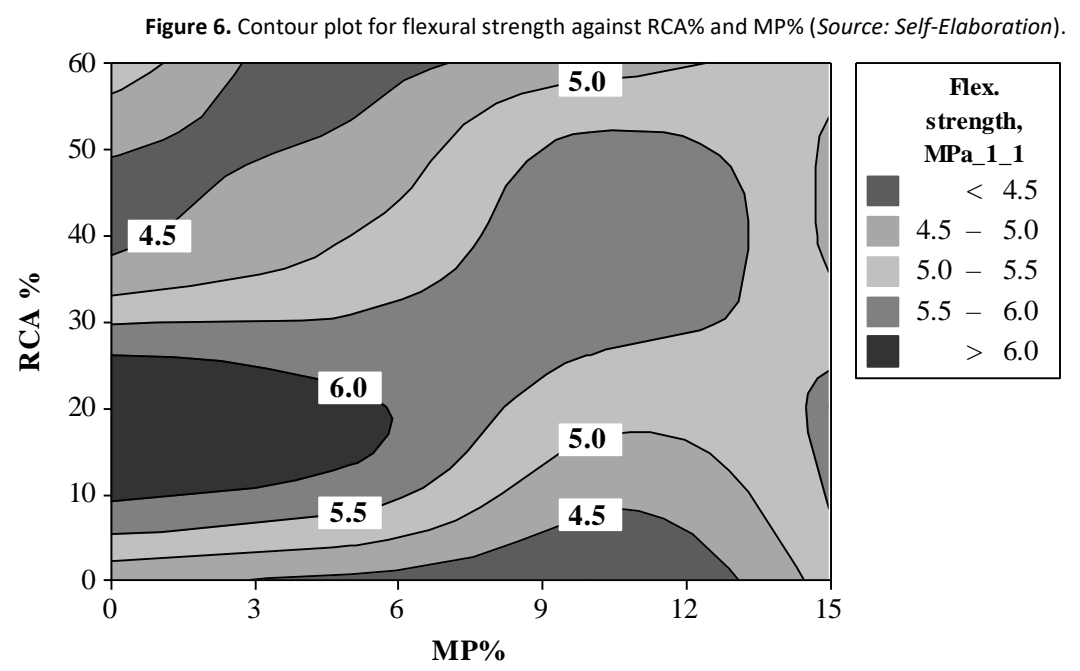

Conclusions

The possibility of fabricating a modern structural-strength geopolymer bricks from some industrial wastes in Egypt country, mainly in Tanta city was investigated in this study under atmospheric curing. Recycled concrete aggregates (RCA), marble powder (MP) and lime powder (LP) are the main industrial wastes that were considered. The following conclusions could be summarized:

- The fly ash based geopolymer bricks produced by using different industrial wastes in this study seem to be suitable for use as construction material. The production of this type of bricks will certainly contribute to the recycling materials and hence minimize the negative impact of the environment in addition to the benefit of geopolymer green materials.

- The application of the Taguchi method for the design of experiments is simple and efficient. Additionally, an adequate number of experiments were carried out.

- The experimental results confirm the optimization of the process parameters using the Taguchi method for enhancing the process performance. The resulting model seems to be capable of predicting the responses of the process with reasonable accuracy.

- The RCA was the most influential factors (Rank 1) on the compressive strength, flexural strength and water absorption. 
- Based on the results of mean, the strongest influence on the compressive strength of geopolymer bricks was exerted by control factor $A(R C A \%)$, control factor $B(M P \%)$, and control factor C (LP\%), respectively. The optimal combination of compressive strength was obtained at $\left(\mathrm{A}_{2} \mathrm{~B}_{4} \mathrm{C}_{1}\right)$ with $20 \% \mathrm{RCA}, 15 \% \mathrm{MP}$ and $0 \% \mathrm{LP}$.

- The compressive strength increases with RCA\% content up to $20 \%$, and then it decreases when RCA\% content is varied from $20 \%$ to $60 \%$.

- The percentage contribution of the control factors affecting the flexural strength and the water absorption of geopolymer bricks were RCA\% (65.4\%), LP\% (13.83\%), MP\% (20.8\%), and RCA\% (59.9\%), LP\% (15.23\%), MP\% (24.9\%), respectively.

- In general, the analysis of these results has revealed that the appropriate incorporation of RCA waste aggregates with using it as NCA replacement can lead to interesting characteristics in terms of strengths and water absorption.

References

Abd Elaty, M.A.A., Ghazy, M.F. \& Abd El Hameed M.F. (2017). Optimization of geopolymer concrete by Principal Component Analysis. ACl Materials Journal, 114(2), 253-264.

Aliabdo, A.A., Abd Elmoaty, A.E.M. \& Auda, E.M. (2014). Re-use of waste marble dust in the production of cement and concrete. Construction and Building Materials, 50, 28-41.

Anuar, K.A., Ridzuan, A.R.M. \& Ismail, S. (2011). Strength characteristic of geopolymer concrete containing recycled concrete aggregate. International Journal of Civil \& Environment Engineering IJCEE-IJENS, 11(1), 81-84.

Basumajumdar, A., Das, A.K., Bandyopadhyay, N. \& Maitra, S. (2008). Some studies on the reaction between fly ash and lime. Bulletin of Material Science, 28(2), 131-136.

Bilgin, N., Yeprem, H.A., Arslan, S., Bilgin, A., Gunay, E. \& Marsoglu, M. (2012). Use of waste marble powder in brick industry. Construction and Building Materials, 29, 449-457.

Cheng, T., Ding, Y., Lee, W. \& Lu, P. (2017). A Study on Marble-Based Geopolymer. MATEC Web of Conferences, 97, 01004, ETIC 2016.

Dutta, D. and Ghosh, S. (2012). Effect of lime stone dust on geopolymerisation and geopolymeric structure. International Journal of Emerging Technology and Advanced Engineering, 2(11), 757-763.

Ghazy, M.F. (2012). Effect of using mortar interface and overlays on masonry behavior by using Taguchi method. ACl Materials Journal, 109(5), 505516.

Ghazy, M.F. \& Abd El Hameed, M.F. (2015). Optimization of lightweight concrete process by Gray- Taguchi method. ACI Materials Journal, 12(3), 365373.

Kaushik, S., Raj, N., Alam, P., Ali, S. \& Palariya, N.C. (2017). Optimization of compressive strength for fly ash building bricks using Taguchi method. International Journal on Emerging Technologies (Special Issue NCETST-2017), 8(1), 394-402.

Lin, Y.H., Tyan, Y.Y., Chang, T.P. \& Chang, C.Y. (2004). An assessment of optimal mixture for concrete made with recycled concrete aggregates. Cement and Concrete Research, 34, 1373-1380.

Muduli, S.D., Nayak, B.D. \& Mishra, B.K. (2014). Geopolymer fly ash building brick by atmospheric curing. International Journal of Chemical Sciences 1, 2(3), 1086-1094.

Poon, C.S., Kou, S.C. \& Lam, L. (2002). Use of recycled aggregates in molded concrete bricks and blocks. Construction and Building Materials, 16, 281289.

Ramezanianpour, A.A., Radaei A.K.E., AzariJafari H. \& Moghaddam M.A. (2014). Influence of Iranian low-reactivity GGBFS on the properties of mortars and concretes by Taguchi method. Computers and Concrete, 13(4), 423-436.

Rao, A., Jha, K.N. \& Misra, S. (2007). Use of aggregates from recycled construction and demolition waste in concrete. Resources Conservation and Recycling, 50(1), 71-81.

Rivera, J., Mejia, J., Mejia, R. \& Gordillo, M. (2014). Hybrid cement based on the alkali activation of by-products of coal. Revista de la Construcción, 13(2), 31-39.

Ross, P.J. (1996). Taguchi Technique for Quality Engineering, $2^{\text {nd }}$ edit, McGraw-Hill, New York.

Shakir, A.A. \& Mohammed, A.A. (2013). Manufacturing of bricks in the past, in the present and in the future: A state of the art review. International Journal of Advances in Applied Sciences (IJAAS), 2(3), 145-156.

Shinde, B.H. \& Kadam, K.N. (2016). Properties of fly ash based geopolymer mortar with ambient curing. International Journal of Engineering Research, 5(1), 203-206.

Surya, M., Rao, K.V. \& Lakshmy, P. (2013). Recycled aggregate concrete for transportation infrastructure. Procedia - Social and Behavioral Sciences, $104,1158-1167$.

Turgut, P. (2010). Masonry composite material made of limestone powder and fly ash Powder. Technology, 204, 42-47.

Turgut, P. (2012). Manufacturing of building bricks without Portland cement. Journal of Cleaner Production, 37, 361-367. 
Uysal, M., Akyuncu, V., Tanyildizi, H., Sumer, M., \& Yildirim, H. (2018). Optimization of durability properties of concrete containing fly ash using Taguchi's approach and Anova analysis. Revista de la construccion Journal of Construction, 17(3): 364-382.

Yamanel, K., Durak, U., ilkentapar, S., Atabey, I. İ., Karahan, O., \& Atiş, C. D. (2019). Influence of waste marble powder as a replacement of cement on the properties of mortar. Revista de la construccion Journal of Construction, 18(2), 290-300.

Ye, G., Liu X., Schutter, G.D., Poppe, A.M. \& Taerwe, L. (2007). Influence of limestone powder used as filler in SCC on hydration and microstructure of cement paste. Cement and Concrete Research, 29(2), 94-102.

Zhang, L. (2013). Production of bricks from waste materials - A review. Construction and Building Materials, 47, 643-655. 